\title{
La importancia del clínico en el desarrollo de las terapias con células madre
}

\section{The clinician's importance in the development of stem cell therapies}

$\mathrm{S}^{\mathrm{r}}$ Editor: Recientemente Browne y Beca ${ }^{1}$ escribieron sobre la prudencia necesaria ante las promesas de la terapia celular, refiriéndose a los resultados mixtos de la terapia celular sobre enfermedades cardiacas, las implicaciones de la comercialización de las terapias, y el fondo ético de estas investigaciones. Sin embargo, considerando el gran desarrollo que están teniendo estas terapias con células madre, considero importante aportar algunas anotaciones.

Las enfermedades cardiovasculares, de igual manera que en Chile, son en México una de las principales causas de morbimortalidad. Esto podría replicarse en otros países en desarrollo donde la transición epidemiológica ha llevado a que, como en los nuestros, coexistan patologías del tercer mundo con las del primer mundo. Esto es particularmente importante en nuestros países, donde los recursos para la salud no son comparables con los de países completamente desarrollados.
Las terapias celulares para enfermedades cardiacas son un ejemplo claro de lo que quisiera manifestar sobre estas terapias, ya que pocos de nosotros, los médicos clínicos en países en desarrollo, vamos a incorporarlas en nuestra práctica clínica cotidiana. Sin embargo, es nuestra responsabilidad estar al tanto de estos avances y más aún conocerlos y comprenderlos a fondo. Ejemplo de esto es la experiencia en México con células madre, la cual representa un enfoque completamente diferente al analizado por Rozenzweig et $\mathrm{al}^{2}$.

$\mathrm{El}$ enfoque probado en México ${ }^{3}$ utilizó células madre de sangre periférica autólogas obtenidas por hemaféresis aplicando como marcador CD34, después de la estimulación de los pacientes con factor estimulante de colonias (GSF); estas células fueron trasplantadas por toracotomía e inyecciones directas al miocardio. Los pacientes incluidos ( $n=39$ ) sufrían insuficiencia cardiaca terminal (clase III NYHA) sin otra opción terapéutica; 
después del trasplante 5 pacientes regresaron a la clase funcional II y 15 a la clase I, con una mejora en la fracción de eyección de 37,7 a 42,15. Siete pacientes requirieron defibrilación durante el procedimiento, y las principales complicaciones fueron arritmias ventriculares ${ }^{3}$. Este estudio nos demuestra la necesidad de profundizar en el conocimiento de las terapias celulares ya que utilizó células CD34 puras, a diferencia de lo reportado en el $\mathrm{NEJM}^{2}$ donde utilizaron médula ósea del paciente, y su pronóstico no mejoró.

Adicionalmente este estudio nos demuestra la utilidad de terapias simples. En México y en la mayoría de los países el trasplante cardiaco es un procedimiento complicado por diversas razones (necesidad de un equipo de trasplante capacitado, implicaciones legales y éticas) que hacen que sea una opción terapéutica para pocos pacientes. Sin embargo, equipos de hemaféresis están disponibles en la mayoría de los hospitales de México (incluyendo públicos) y en muchos países de Latinoamérica, y en estos casos las dificultades asociadas al trasplante de células madre, como son el rechazo, la reacción de injerto contra huésped y el riesgo de neoplasia, son mucho menores o prácticamente nulas ya que se trata de un autotrasplante y la médula de estos pacientes se encuentra en condiciones óptimas. Esto demuestra que los clínicos tenemos la posibilidad de aplicar y desarrollar estas terapias, ya que somos nosotros quienes tratamos a los pacientes y sólo una visión abierta a los avances de la ciencia nos permitirá hacerlas una realidad.

Otra implicación de gran importancia es la incorporación de compañías comerciales en el desarrollo de terapias celulares. Browne y Beca ${ }^{1}$ señalan un grave conflicto de intereses: el beneficio económico y las implicaciones éticas del involucramiento de las compañías. Sin embargo, esto requiere un análisis más profundo. Tenemos que considerar que es difícil eliminar el interés comercial de la investigación y la práctica médica. Un ejemplo claro sería el caso de la clonación de la oveja Dolly ${ }^{4}$ : los años y recursos económicos invertidos en este parteaguas de la biotecnología moderna vinieron en gran parte de un interés económico en "gene farming" (la producción de proteínas humanas en biorectores vivos) del socio comercial del Roslin Institute, la compañía denominada PPL therapeutics, teniendo como objetivo la producción de factor IX humano en ovinos transgénicos, conseguido el mismo año ${ }^{5}$.

¿Cuál es la importancia de este ejemplo? Hoy nos parecería imposible que no se diera financiamiento a la transferencia somática nuclear y transgénesis, pero en su momento estas técnicas se consideraban imposibles y con un mínimo potencial. Allí es donde el financiamiento por inversionistas aventurados, ajenos en muchas ocasiones al mundo de la ciencia, cobra importancia. De tal manera que volvemos a la importancia de los clínicos en el desarrollo de las terapias celulares: si nos preguntaran si se debería invertir en estas terapias, la mayoría de nosotros contestaría que no, ya que su potencial es limitado y su aplicación en la práctica clínica está a años de ser una realidad; por lo tanto nosotros mismos somos en parte responsables de la búsqueda de financiamiento en compañías privadas.

Lamentablemente este es un mal en muchos ámbitos. Ejemplo son las instancias de gobiernos encargados de financiar investigaciones y las propias universidades renuentes a financiar proyectos de alta tecnología. Incluso el gobierno de EE.UU de Norteamérica ha dado muestra de esta actitud, por el veto del presidente George Bush al Stem Cell Research Enhancement Act, aprobado por el Senado, que revertía la ilegalidad de usar dinero federal en la investigación en células madre. Sin embargo, es importante hacer notar que en el caso de EE.UU de Norteamérica el California Institute of Regenerative Medicine (http://www.cirm.ca.gov), agencia estatal del Estado de California, ha dado impulso con una inversión inicial de 3 billones de dólares para la investigación en células madre, convirtiendo a este Estado en un polo del desarrollo económico y biotecnológico de las terapias celulares.

Para Latinoamérica, algunos ejemplos nos deberían hacer reflexionar: la India, el país más poblado del mundo y con la mayoría de los problemas del tercer mundo, ha tenido la capacidad y el interés de desarrollar 10 líneas de células madre entre instituciones de gobierno y empresas privadas (http://stemcells.nih.gov/research/registry/unavailable/).

Ello demuestra que el desarrollo de estas terapias es altamente dependiente del interés de las autoridades más que de una posición solamente económica. Un último punto que me gustaría 
notar es la existencia de la REDLARA, (http:// www.redlara.com), agrupación que integra a los centros de Reproducción Asistida de Latinoamérica. En el año 2005 incluía 135 centros y el desarrollo de células madre siempre ha estado ligado a estos centros ya que se obtienen de embriones congelados sobrantes de ciclos de reproducción asistida; de estos centros solamente uno, el CECOLFES (http://www.cecolfes.com), Centro Colombiano de Infertilidad, liderado por el Dr. Elkin Lucena, ha desarrollado recientemente la primera línea de células madre embrionarias de Latinoamérica: CECOL-14 (Lucena C et al. 2005. Culture of Human Embryonic Stem Cells from Vitrified Blastocysts. $13^{\text {th }}$ World Congress on in vitro Fertilization Assisted Reproduction \& Genetics, Istanbul, Turkey). Lamentablemente en mi país y en muchos otros de Latinoamérica nos consideramos incapaces o desinteresados en desa-

\section{REFERENCIAS}

1. Browne J, Beca JP. Necesidad de prudencia frente a las promesas de la terapia celular. Rev Méd Chile 2007; 135: 127-8.

2. Rozenzweig A. Cardiac cell therapy-mixed results from mixed cells. N Engl J Med 2006; 335: 1274-7.

3. Arguero R, Careaga-Reyna G, Castano-Guerra $R$, Garrido-Garduno MH, Magana-Serrano JA, DE Jesus NAmBo-Lucio M. Cellular autotransplantation rrollar esta tecnología; pero estos dos ejemplos demuestran que los países en desarrollo podemos ser generadores de conocimiento de punta en terapia celular.

En conclusión, somos los médicos clínicos quienes con una visión abierta y gran conocimiento, podemos hacer que Latinoamérica avance en la creación y desarrollo de terapias con células madre, convirtiéndolas en una mejora de la salud y calidad de vida de nuestros pacientes.

\section{Raúl E. Piña-Aguilar}

Facultad de Medicina, Universidad Autónoma de Yucatán. Avenida Itzáes, Número 498, Mérida, Yucatán, México. Código Postal 97000, Apartado postal 2-1225. Teléfono: +52 (999) 924-0554. Fax: +52 (999) 923-3297. E mail: rpina@fmedicina.uady.mx - rpina.a@hotmail.com

for ischemic and idiopathic dilated cardiomyopathy. Preliminary report. Arch Med Res 2006; 37: 1010-14.

4. Wilmut I, Schnieke AE, McWhir J, Kind AJ, CAmpbel $\mathrm{KH}$. Viable offspring derived from fetal and adult mammalian cells. Nature 1997; 385: 810-13.

5. Schnieke AE, Kind AJ, RtTchie WA, Mycock K, ScotT AR, Ritchie M ET AL. Human factor IX transgenic sheep produced by transfer of nuclei from transfected fetal fibroblasts. Science 1997; 278: 2130-33. 